\title{
Pure Cross-Docking as Strategy of Distribution for Courier Services: Quantitative Study on Perceived Benefits Associated with Time Management
}

\author{
Muhammad Faisal Sultan \\ Assistant Professor KASBIT \& PhD Scholar KUBS-UoK \\ Sadia Sheikh \\ Phd Scholar and Assistant Professor, Greenwich University \\ Naveed John \\ MBA Student, KASBIT
}

\begin{abstract}
Cross-Docking is one of the most important strategies of distribution. However extensive risk is associated with the implementation of the strategy especially in developing countries. Therefore research most of the times has been done on partial cross docking practices and studies recommended the conduction of future research work on practical implications of cross docking with inclusion of limitations in research models. Therefore the purpose of this study is to figure out potential advantages of pure cross docking on time management. For this purpose supply chain managers of courier services companies are the target population and the data has been taken through consulting with these mangers during their office times. Although the questionnaire was adopted and merely focusing on potential benefits of cross docking but considerable percentage of respondents hesitates in providing their reviews. Thus the study has been completed from the responses of fifty respondents working on managerial position in courier service companies
\end{abstract}

Keywords: Pure Cross-Docking, Uncertain Countries, Perceived Benefits of Cross-Docking

DOI: $10.7176 / \mathrm{EJBM} / 11-13-05$

Publication date:May $31^{\text {st }} 2019$

\section{Introduction:}

Ertek (2012) indicated that along with traditional distribution with warehouses and direct shipment, crossdocking is included in three major strategies for distribution. Further added by Gue (1999) that cross-docking eliminates the function of storage and order picking although this elimination does not affect function of receiving and shipping (Bartholdi \& Gue, 2005). Study further revealed that the strategy of cross-docking has been made famous by Wal-Mart and the strategy is now included in the list of company's core competencies.

Similar has been highlighted by the recent definition of Chopra and Miendl (2016) that strategy through which products has been exchanged between trucks in such a manner that truck going to retailer has material from different suppliers. Therefore legitimate to believe that cross-docking provided liberty of everyday low pricing as mentioned by Bartholdi and Gue (2005). This significance was further elaborated by Vrisagotis Siassiakos Panta Kaimkamis and Kapetanios (2009) that strategy revokes the requirement of warehousing through immediate transshipment.

Thus sometimes mentioned as just in time technique (JIT) as it spend less than 24 hours in cross-dock therefore reduces the operational costs (Li, He, Sim \& Chen, 2012). Ertek (2012) provide examples of giants like Wal-Mart Sears and Asda from retail segment, Toyota and Mitsubishi from automobile sector as those who gain edge through the strategy. Though Wal-Mart is the pioneer of the strategy (Stalk \& Lachenauer, 2004), but cross-docking is also renowned strategy for distribution in some other industries like electronics and apparel etc (Ertek. 2012). Shekholeslam and Emamian (2013) highlighted two levels of cross-docking as pre-distribution cross-docking (Pre-C), used by manufacturers and post-distribution cross-docking (Post-C) used by distributors.

Furthermore Shuib and Fatthi (2012) and Virsagotis et al (2009) provided five types of cross-docking as cross-docking for Manufacturer, Distributor, Transportations, Retail, and Opportunistic Cross-Docking. Study also provides purpose of these types which are as under:

a) Manufacturers Cross-Docking is the activity to consolidate inbounds logistic to support JIT. This actually happen due to constant demand of the product (manufactured) in the market.

b) Distributor Cross-Docking is actually mend to sum up different shipments from multiple vendors in a single multi-SKU pallet

c) Transportation Cross-Docking is used to consolidate shipments through summing up order from different shipper. This technique is popular in small package industry and shipments are made through LTL (less than a truck load). 
d) Retail Cross-Docking is the technique proved worthy for giants like Wal-Mart. The technique is used to sort out products from different vendors onto outbound trucks with respect to the requirements of different outlets.

e) Opportunistic Cross-Docking can be formed at any warehouse where shipment is directly moved to shipping doc from receiving doc.

Study of Apte and Viswanathan (2000) indicated that most of the warehouses are not using cross docking as the exclusive strategy of distribution. This is actually happened due to the difference of incoming load and outgoing load thus according to the study of Apte and Viswanathan stable demand is the prerequisite of crossdocking. Study further revealed that the another factor which must considered for implementation of crossdocking is unit stock out cost as cross-docking leads to minimal level of inventory management.

Therefore loss of sales might also occur due to stock-out of products, hence study indicated that if the stock out cost is low then cross-docking might also be preferred strategy for distribution. This is even described by the matrix for distribution as shown in the form of figure 1.

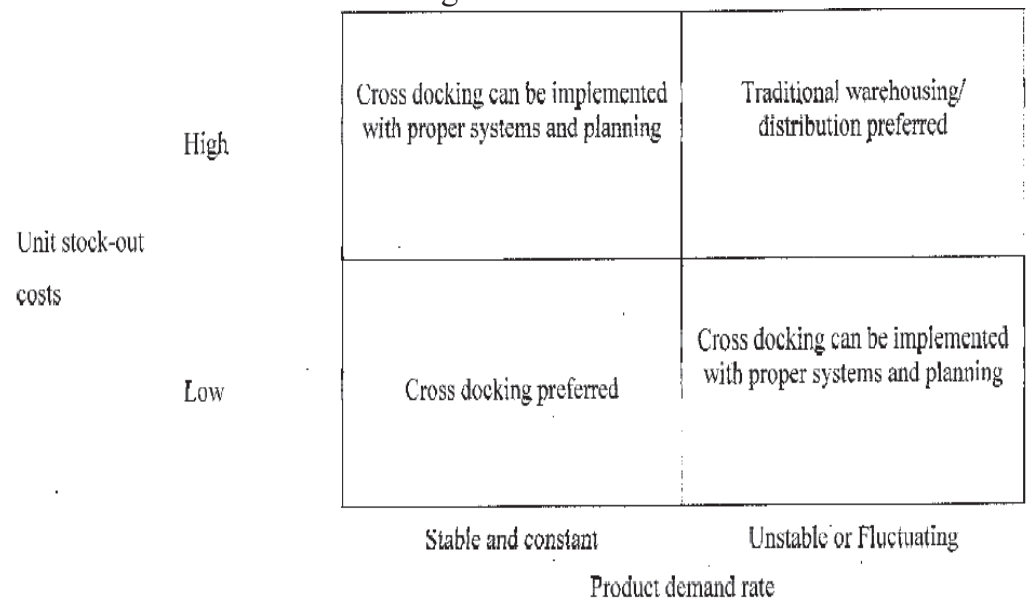

Figure 1: Distribution Strategy on the bases of product demand rate and unit stock out rate (Apte \& Viswanathan, 2000).

\section{Statement of Problem:}

Cross-docking is associated with uncertainties e.g. trucks might not arrive on time, container processing might be mismatched with plan and resources might become out of order. These issues became more prevalent in under developed countries where logistic companies are still used manual methods for planning (Li et al., 2012). Problem became more sever when it has been observed that various studies postulated strategy as beneficial for time management (Shuib \& Fatthi, 2012). Although minimal studies with respect to uncertain countries like Pakistan (Khan, Hussainy, Khan, Khan, Sharif \& Tariq, 2017) and studies which focused towards uncertain countries are mostly qualitative e.g. Khan et al (2017), Qijun, Zhang, Song and Gui (2009) etc.

Therefore looks legitimate to conduct quantitative analysis for analysis of benefits yield by cross-docking. Supplemented by Sheikholeslam and Emamian (2013), that studies on cross-docking have some real world limitations \& assumptions which are ignored while solving real life problems. Although products in high demand or perishable nature are best suited for cross-docking (Aichlmayr, 2001) therefore 3PL and LTL companies are constantly following cross-docking (Terreri, 2001). Hence it is required to conduct quantitative analysis on benefits of cross-docking especially for the logistic companies as highlighted by Li et al (2012).

\section{Theoretical Framework}

Sheikholeslam and Emamian (2013) indicated that problems in cross docking are interdependent and future studies might use combination of problems and limitation to increase interest. Li et al (2012) posits that coordination is required in order to improve efficiency of cross docking as well as throughput which avoid bottleneck and manages resource constraints. Study of Khan et al (2017) indicated that cross docking is associated with high risk and to follow pure cross-docking strategy in uncertain countries is impractical. Study further revealed there is a requirement of small level warehousing in cross-docking for managing issues in demand and supply. Thus it is assumed that all of the studies are highlighting requirement of proper communication. Therefore in accordance with Sheikholeslam and Emamian (2013) study included proper communication as moderating variable.

\section{Delimitations}

The selection of couriers services is coherent with Li et al (2012), as well as study of Virsagotis et al (2009) that 
courier services does not only have high volumes of product but also have relatively lesser fluctuation in demand. Moreover FedEx is also using the facility of cross-docking in other contents. Therefore it is significantly impact to understanding regarding the implication of the concept in the scenario of Pakistan.

\section{Significance}

The study is one of the pervasive studies as it will reveal the perception regarding the implementation of pure cross-docking strategy in uncertain counties like Pakistan. Therefore study has the potential to uncover the reasons why professionals hesitate in implementing of the strategy as highlighted by Khan et al (2017). Thus it is appropriate to believe that results will definitely contributes to knowledge base and will also provide base of professional understanding to other industries like retail etc. regarding the implications of pure cross-docking. This postulate is valid according to Virsagotis et al (2009) as courier services has high demand as well as low rate of fluctuations which are linked with the products being sold on retail. Hence study has also the potential to be associated with any industry having high demand and lesser rate of fluctuations like FMCG etc.

\section{Research Model}

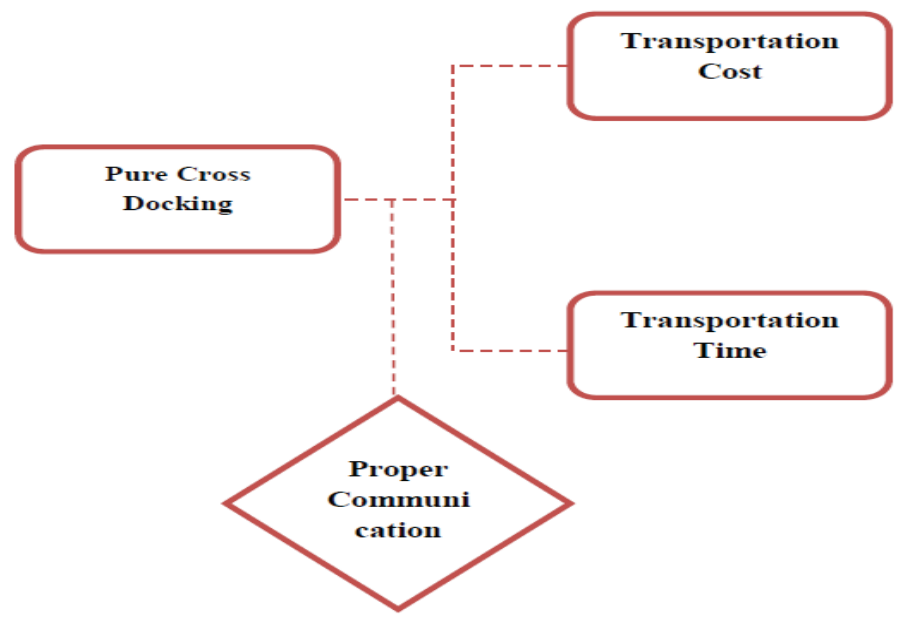

\section{Research Hypotheses}

H1A: There is a relationship between implementation of pure cross-docking by courier companies and transportation cost

H2A: There is a relationship between implementation of pure cross-docking by courier companies and transportation time

H3A: Proper Communication does moderates the relationship between and transportation cost and pure crossdocking by courier companies

H4A: Proper Communication does moderates the relationship between transportation time and pure crossdocking by courier companies

\section{Literature Review}

This has already been indicated that cross-docking can be implemented by different industries like manufacturing, distribution and transportation etc. (Virsagotis et al., 2009 and Shuib \& Fatthi, 2012). Study conducted by Sung and Song (2003) postulated that cross-docking has the capacity to decrease cost of transportation as well as delivery time. Kreng and Chen (2008) also indicated that cross-docking has been used by the giants like Wal-Mart to achieve economies of scale through avoiding unusual inventory and handling cost. Similarly Cross Dock Manitoba (2014) also agreed on the point that shipping through cross-docking might decrease the cost of transportation. This might be achieved through delivering products related to nearby vicinities via full-truck load which also yield to decrease in time and cost of transportation. Although crossdocking is beneficial under large distribution having several vehicles for collecting and dispatching products (Kreng \& Chen, 2008).

The phenomenon has been further clarified by Gumus and Bookbinder (2004) by citing Daganzo (1985) that freight cost is combination of variable cost and fixed cost. Elements which are included in variable cost are vehicle operation \& driver's wage fixed cost is proportional to number of trucks used in the operations. Therefore Gumus and Bookbinder (2004) postulated that consolidation and careful selection of transportation points might allow 3PL companies not only to increase their shipment but also reduction in their trucks. 


\section{Methodology}

Considering studies on cross-docking in the Asian scenario it has been revealed that most of the work conducted is qualitative in nature. Although research covered diversified areas like implication, problems, issues and factors affecting cross docking but there is a phenomenal lacking of quantitative measures. Literature indicated that prior studies can be classified into three categories i.e. implications, benefits \& problems, factors important for cross docking \& review of quantitative approaches for cross-dock assignment.

Classifying further Khan et al (2017), Ramaa Subramanya and Rangaswamy (2012), Sheikholeslam and Emamian (2013), Qijun Zhang Song and Gui (2009) etc. explored implications, benefits \& problems. Yang Balakrishan and, Cheng (2010) explored factors important for cross docking and Shuib and Fatthi (2012) provided review of quantitative approaches. Therefore questionnaire has been developed through considering studies associated with other continents e.g. Waller Cassady and Ozment (2006) Guignard Hahn and Zhang (2014) and Gumus and Bookbinder (2004).

\section{Sampling}

The sampling technique for the study is non-probability sampling as there is no proper base to highlight sampling technique for data collection associated with cross-docking implications in Pakistan. Therefore in accordance with the unavailability of quantitative studies on cross-docking in Pakistan the method for data collection is snow-ball sampling. The method has been preferred to include most appropriate applicants rather than generalize audience from all the logistic function of courier services.

\section{Questionnaire}

Questionnaire was not adopted in complete, therefore initially tested for internal consistency with the sample of 25 respondents from SCM department of couriers companies. Questionnaire has also been transformed to likert scale as the purpose of the questionnaire was to measure attitudes Likert (1932) regarding pure cross-docking. Moreover the transformation to likert scale has also been done to increase its applicability to wider range of constructs (Revilla, Staris and Krosnick, 2014). This optimizes face validity of questionnaire and the values of initial testing (pilot testing) are shown through table 1. After validation, data has been collected for further twenty five respondents through using same sampling method which will make total sample size fifty (50) and optimize reliability.

\section{Statistical Testing and Analysis}

Litwin (1995) indicated that Cronbach Alpha is the best measure to check the internal consistency of the instrument. Therefore reliability of all the variables has been gauged through taking the reference of Maiyaki and Mohd Mokhtar (2011). Results of Pilot Study might be observed through Table 1.

\begin{tabular}{|l|c|c|}
\hline \multicolumn{2}{|c|}{ Reliability Statistics } & \\
\hline & No of Items & Cronbach's Alpha \\
\hline Pure Cross Docking & $\mathbf{5}$ & 0.731 \\
\hline Transportation Time & $\mathbf{4}$ & 0.789 \\
\hline Transportation Cost & $\mathbf{4}$ & 0.702 \\
\hline Proper Communication & $\mathbf{5}$ & 0.692 \\
\hline
\end{tabular}

Table 1 Reliability Values for Pilot Testing

Table 1 highlighted that value of Cronbach Alpha is more than 0.60 for each case. Therefore in accordance with Maiyaki et al (2011) it is legitimate to declare pilot test successful for the designed instrument. After successful pilot testing researchers conduct the entire study on larger sample size i.e. 50 (twice of the sample used in pilot testing). Again reliability of data has been checked through Cronbach Alpha to affirm the data for further inferential testing. The reliability analysis for entire sample might be observed through Table 2.

\begin{tabular}{|l|c|c|}
\hline \multicolumn{2}{|c|}{ Reliability Statistics } & \\
\hline & No of Items & Cronbach's Alpha \\
\hline Pure Cross Docking & $\mathbf{5}$ & 0.783 \\
\hline Transportation Time & $\mathbf{4}$ & 0.811 \\
\hline Transportation Cost & $\mathbf{4}$ & 0.791 \\
\hline Proper Communication & $\mathbf{5}$ & 0.779 \\
\hline
\end{tabular}

Table 2 Reliability Analysis for complete sample

Table 2 highlighted that value of Cronbach Alpha is more than 0.7 in every case. Therefore study proceeded towards inferential testing in accordance with Pietersen and Maree (2007) that value of Cronbach Alpha more than 0.7 is optimal. SPSS 17 has been used to conduct further inferential testing and Hayes model has been for analysis. The reason for preferring Hayes Model over any other form of statistical tool like SEM is that the model has only one moderator and all the variables used in the model are observed variables (Hayes \& Scharkow, 
2013).

Thus in order to avoid any complexities and errors Hayes Model has been preferred over AMOS and SMART PLS. Moreover purpose of the study is not to develop any new theory \& all the variables are already been evaluated in western context. Although for uncertain countries the concept is bit new but the focus of study is not associated with theory building, therefore SMART PLS cannot be incorporated. On the other side smaller sample size restricted the use of AMOS; therefore the use of Hayes Model is legitimate according to statisticians $\&$ technological constraints.

Run MATRIX procedure:

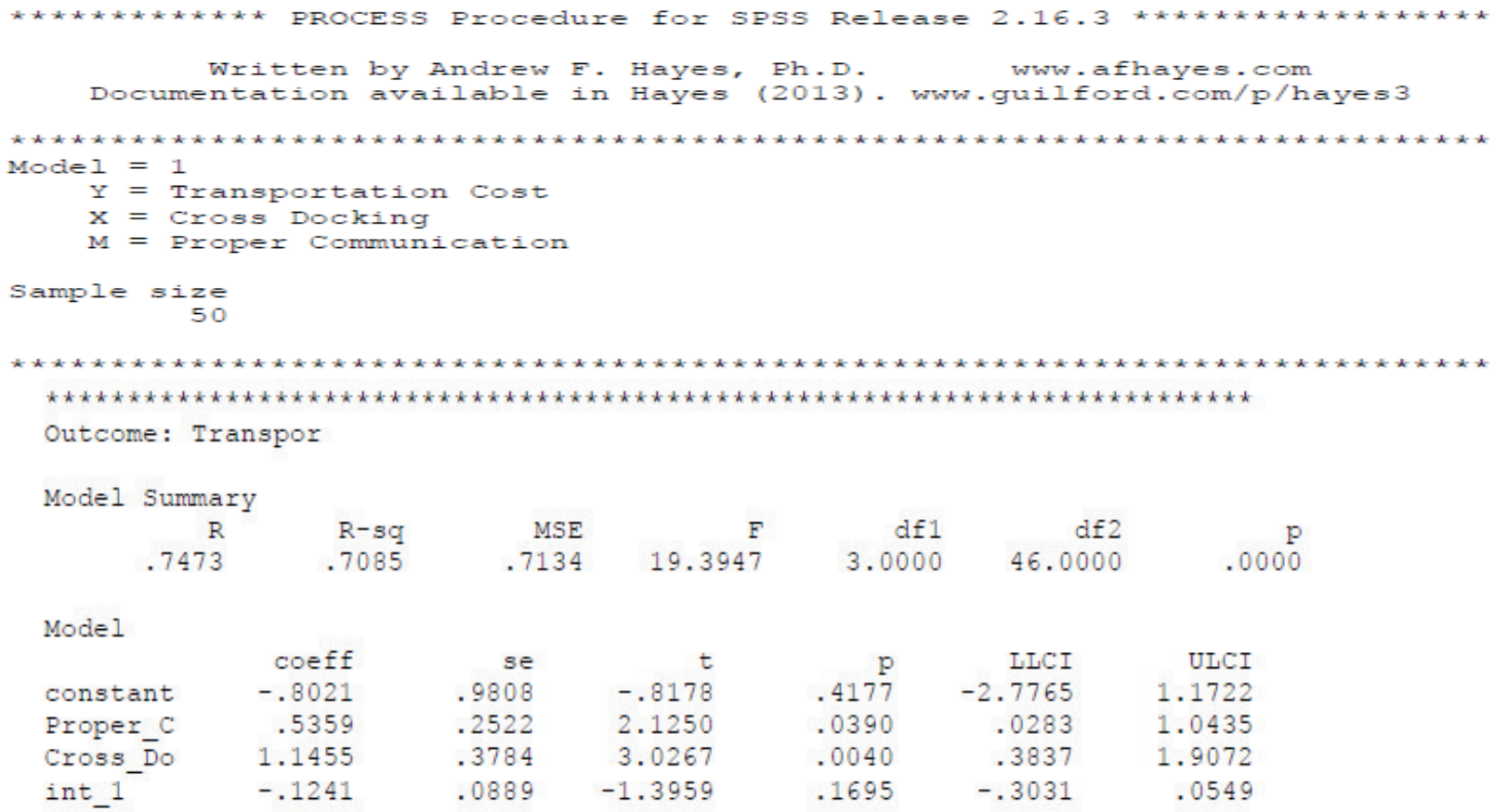

Product terms key:

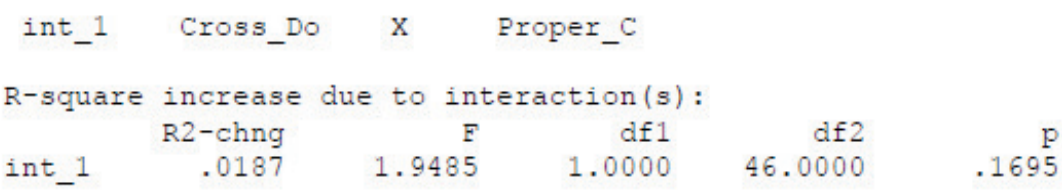

Table 3 Hayes Model: Illustrating the effect of Pure Cross Docking on Transportation Cost

Table 3 indicated that model is fit for statistical testing, as F-value is large enough (i.e. 19.3947). Values of $\mathrm{R}$ and R-Square are more than $70 \%$ and there is no much difference between $\mathrm{R}$ and $\mathrm{R}$-Square. Hence the model has predicted majorly by independent variables. Moreover it has also been observed that pure cross docking is not perceived as the strategy which can decrease the transportation cost. However through associating it with proper communication the strategy might became able to decrease the transportation cost. 


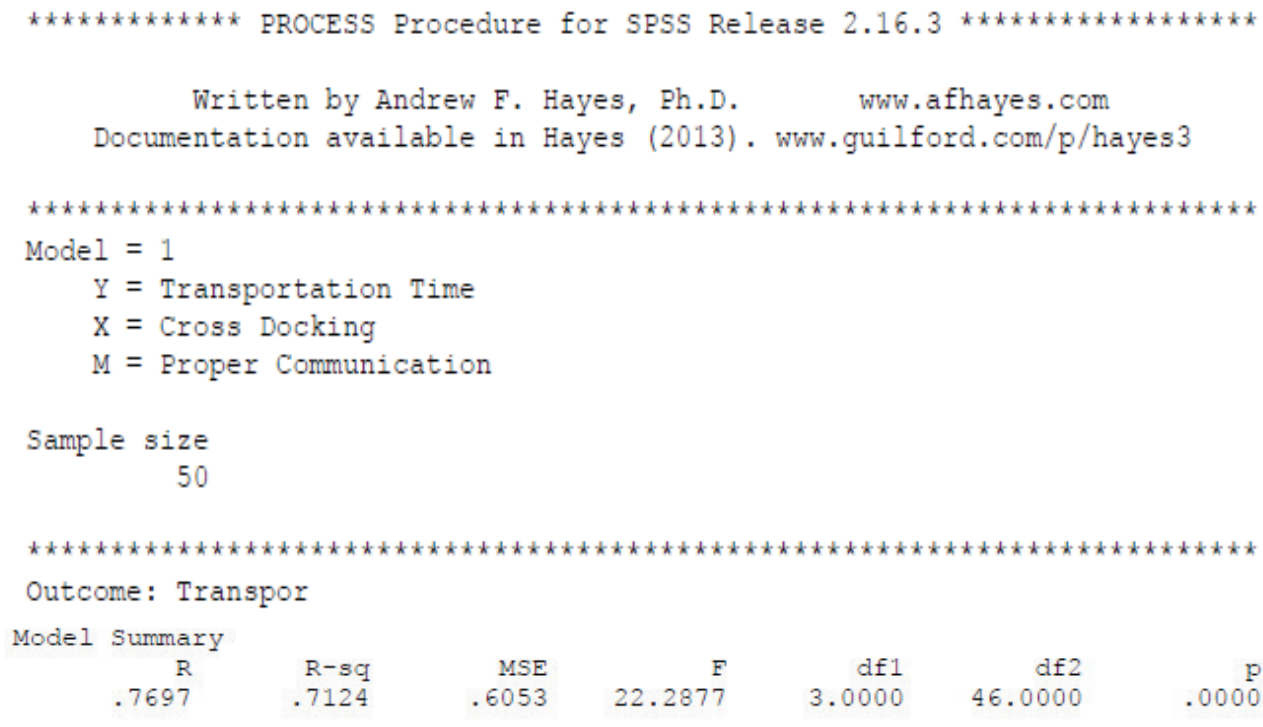

Table 4 Hayes Model: Illustrating the effect of Pure Cross Docking on Transportation Time

Table 4 indicated that model is fit for statistical testing as F-value is large enough (i.e. 22.2877). Values of $\mathrm{R}$ and R-Square are also more than $70 \%$ and there is no much difference between R and R-Square. Hence the model has predicted majorly by independent variables.

Moreover it has also been observed that pure cross docking is not perceived as the strategy which can decrease the transportation time. However through associating it with proper communication the strategy might became able to decrease the transportation time.

\section{Discussion}

From the use of Hayes Model it has been analyzed that pure cross-docking is not perceived as the strategy which aids in time management for courier companies. The statistical test revealed that the strategy is perceived fruitful neither for reduction transportation time nor for transportation cost. This it is legitimate to believe the point mentioned by Khan et al (2017), that pure cross-docking is not perceived as fruitful strategy in uncertain countries. However inclusion of problems and limitations in the model (Sheikholeslam \& Emamian, 2013) like 
proper communication (Khan et al , 2017) will provide significant aid to the conceptualization of ideas (Li e al., 2012).

\section{Area for Future Study:}

a) The study is conducted on transportation cross-docking i.e. courier services which has somewhat relevant with the characteristics of the products sold by retailers. Therefore the similar sort of studies might be conducted on retailers cross-docking for e.g. Metro to match findings of un-certain countries retailers with giant like Wal-Mart etc.

b) Moreover using the indication of Sheikholeslam and Emamian (2013) study might also use some other moderating factors in order to evaluate the impact of pure cross-docking.

\section{References:}

1. Aichlmayr, M. (2001). Never touching the floor. Transportation \& Distribution. 47-52

2. Apte, U. M., \& Viswanathan, S. (2000). Effective cross docking for improving distribution efficiencies. International Journal of Logistics, 3(3), 291-302.

3. Bartholdi, J. J., \& Gue, K. R. (2004). The best shape for a crossdock. Transportation Science, $38(2), 235-$ 244.

4. Cavana, R. Y., Delahaye, B. L., \& Sekaran, U. (2001). Applied business research: Qualitative and quantitative methods. John Wiley \& Sons Inc

5. Charmaz, K. (2006). Constructing grounded theory: A practical guide through qualitative analysis. Sage.

6. Chopra, S., \& Meindl, P. (2016). Supply chain management: Strategy, planning, and operations, ISBN 0-13101028-X.

7. Cohen, L., Manion, L., Morrison, K., \& Morrison, R. B. (2007). Research Methods in education , Rout ledge.

8. Cross Dock Manitoba. (2014). How does Cross-Docking saves money?, https://www.crossdock.mb.ca/blog/how-does-cross-docking-save-money/

9. Ertek, G., (2012) "Crossdocking Insights from a Third Party Logistics Firm in Turkey”, in Managing Supply Chains on the Silk Road: Strategy, Performance, and Risk, Eds: Çağrı Haksöz, Sridhar Seshadri and Ananth V. Iyer

10. Ertek, G., (2012) “Crossdocking Insights from a Third Party Logistics Firm in Turkey”, in Managing Supply Chains on the Silk Road: Strategy, Performance, and Risk, Eds: Çağrı Haksöz, Sridhar Seshadri and Ananth V. Iyer

11. Gue, K. R. (1999). The effects of trailer scheduling on the layout of freight terminals. Transportation Science, 33(4), 419-428

12. Guignard, M., Hahn, P. M., \& Zhang, H. (2013). Practical cross-docking optimization. TRISTAN VIII. San Pedro de Atacama, Chile, 4-7.

13. Guignard, M., Hahn, P., \& Zhang, H. (2014). Dynamic vs. Static Optimization of Cross-docking Operations.

14. Gümüş, M., \& Bookbinder, J. H. (2004). Cross-docking and its implications in location-distribution systems. Journal of Business Logistics, 25(2), 199-228.

15. Hayes, A. F., \& Scharkow, M. (2013). The relative trustworthiness of inferential tests of the indirect effect in statistical mediation analysis: Does method really matter? Psychological Science, 24, 1918-1927

16. Johnston, R. B., Mak, H. C., \& Kurnia, S. (2000). The contribution of Internet electronic commerce to advanced supply chain reform-a case study. E-Commerce and V-Business, 232-249.

17. Khan, H., Hussainy, S. K., Khan, K., Khan, E. Sharif, M. \& Tariq, S., (2017), The Implications of CrossDocking in the Manufacturing Sector of Pakistan. International Journal of Supply Chain Management, 6(3), 131-136

18. Kreng, V. B., \& Chen, F. T. (2008). The benefits of a cross-docking delivery strategy: a supply chain collaboration approach. Production Planning and Control, 19(3), 229-241., doi: $10.1080 / 09537280801916157$

19. Li, Z., He, W., Sim, C. H., \& Chen, C. C. (2012). A solution for cross-docking operations planning, scheduling and coordination. Journal of Service Science and Management, 5(02), 111-117

20. Li, Z., He, W., Sim, C. H., \& Chen, C. C. (2012). A solution for cross-docking operations planning, scheduling and coordination. Journal of Service Science and Management, 5(02), 111-117

21. Likert, R. (1932). A technique for the measurement of attitudes. Archives of psychology, 22 (140), 55

22. Litwin, M. S. (1995). How to measure survey reliability and validity (Vol. 7). Sage.

23. Maiyaki, A. A., \& Mohd Mokhtar, S. S. (2011). Determinants of customer behavioural responses: A pilot study. International business research, 4(1), 193-197.

24. McMillan, J. H. and Schumacher, S., (2006), "Research in Education” $6^{\text {th }}$ Ed., Pearson, New York.

25. Morton, R. (1996). Design customer service into your space. Transportation \& Distribution, 37(5), 124-129. 
26. Pietersen, J., \& Maree, K. (2007). Statistical analysis II: Inferential statistics. First steps in research. Pretoria: Van Schaik, 197-213.

27. Qijun, Q., Zhang, Z., Song, X., \& Gui, S. (2009, December). Application research of cross docking logistics in food cold-chain logistics. In 2009 International Conference on Information Management, Innovation Management and Industrial Engineering (Vol. 3, pp. 236-240). IEEE.

28. Ramaa, A., Subramanya, K. N., \& Rangaswamy, T. M. (2012). Impact of warehouse management system in a supply chain. International Journal of Computer Applications, 54(1).

29. Ramaa, A., Subramanya, K. N., \& Rangaswamy, T. M. (2012). Impact of warehouse management system in a supply chain. International Journal of Computer Applications, 54(1).

30. Revilla, M. A., Saris, W. E., \& Krosnick, J. A. (2014). Choosing the number of categories in agree-disagree scales. Sociological Methods \& Research, 43(1), 73-97.

31. Richardson, H.L. (2004). Execution at the dock. Logistics Today, 45(4), 31-33

32. Schwind, G. F. (1996). A systems approach to docks and cross docking. Material Handling Engineering, $51(2), 59-62$.

33. Scotland, J. (2012). Exploring the Philosophical Underpinnings of Research: Relating Ontology and Epistemology to the Methodology and Methods of the Scientific, Interpretive, and Critical Research Paradigms. English language teaching, 5(9), 9-16

34. Sekaran, U., \& Bougie, R. (2016). Research methods for business: A skill building approach. John Wiley \& Sons

35. Shanahan, J. (2004). Cross docking spruces up Urban Outfitters. Logistics Management, 43(1), 65

36. Sheikholeslam, M. N., \& Emamian, S. (2013). Review and Classification of Cross-Docking Concept. International Journal of Learning Management Systems. 4(1), 25-33

37. Shuib, A., \& Fatthi, W. N. A. W. A. (2012). A review on quantitative approaches for dock door assignment in cross-docking. International Journal on Advanced Science, Engineering and Information Technology, 2(5), 370-374.

38. Stalk, J.G. and Lachenauer, R., (2004). Hard ball: five killer strategies for trouncing the competition. Harvard Business Review, 82 (4), 62-71

39. Sung, C.S. and Song, S.H. (2003). Integrated service network design for a cross-docking supply chain network. Journal of the Operational Research Society, 54, 1283-1295.

40. Terreri, A. (2001). PROFITING from CROSS DOCKING. Warehousing Management, 8(8), 29-32.

41. Ullman, S. (2001). In BG Tabachnick, \& LS Fidell (Eds.), Using multivariate statistics (pp. 653-771 ed., p. 966).

42. Vrisagotis, V., Siassiakos, K., Panta, M., Kaimakamis, G., \& Kapetanios, G. (2009). The problem of crossdocking analyzed by Markov chain method. The application to a major Greek retailer. supply chain management, 5,6 .

43. Waller, M. A., Cassady, C. R., \& Ozment, J. (2006). Impact of cross-docking on inventory in a decentralized retail supply chain. Transportation Research Part E: Logistics and Transportation Review, 42(5), 359-382

44. Witt, C. E. (1998). Crossdocking: Concepts demand choice. Material Handling Engineering, 53(7), 44-49

45. Yang, K. K., Balakrishnan, J., \& Cheng, C. H. (2010). An analysis of factors affecting cross docking operations. Journal of business logistics, 31(1), 121-148. 